\title{
Prostaglandin E2-induced colonic secretion in patients with and without colorectal neoplasia
}

\author{
Nicolai Kaltoft ${ }^{1}$, Maria C Tilotta' ${ }^{1}$, Anne-Barbara Witte ${ }^{1,2}$, Philip S Osbak', Steen S Poulsen ${ }^{3}$, Niels Bindslev ${ }^{4}$,
} Mark B Hansen ${ }^{1,5^{*}}$

\begin{abstract}
Background: The pathogenesis for colorectal cancer remains unresolved. A growing body of evidence suggests a direct correlation between cyclooxygenase enzyme expression, prostaglandin $E_{2}$ metabolism and neoplastic development. Thus further understanding of the regulation of epithelial functions by prostaglandin $E_{2}$ is needed. We hypothesized that patients with colonic neoplasia have altered colonic epithelial ion transport and express functionally different prostanoid receptor levels in this respect.

Methods: Patients referred for colonoscopy were included and grouped into patients with and without colorectal neoplasia. Patients without endoscopic findings of neoplasia served as controls. Biopsy specimens were obtained from normally appearing mucosa in the sigmoid part of colon. Biopsies were mounted in miniaturized modified Ussing air-suction chambers. Indomethacin $(10 \mu \mathrm{M})$, various stimulators and inhibitors of prostanoid receptors and ion transport were subsequently added to the chamber solutions. Electrogenic ion transport parameters (short circuit current and slope conductance) were recorded. Tissue pathology and tissue damage before and after experiments was assessed by histology.
\end{abstract}

Results: Baseline short circuit current and slope conductance did not differ between the two groups. Patients with neoplasia were significantly more sensitive to indomethacin with a decrease in short circuit current of $15.1 \pm 2.6$ $\mu \mathrm{A} \cdot \mathrm{cm}^{-2}$ compared to controls, who showed a decrease of $10.5 \pm 2.1 \mu \mathrm{A} \cdot \mathrm{cm}^{-2}(p=0.027)$. Stimulation or inhibition with theophylline, ouabain, bumetanide, forskolin or the EP receptor agonists prostaglandin $E_{2}$, butaprost, sulprostone and prostaglandin $E_{1}(\mathrm{OH})$ did not differ significantly between the two groups. Histology was with normal findings in both groups.

Conclusions: Epithelial electrogenic transport is more sensitive to indomethacin in normal colonic mucosa from patients with previous or present colorectal neoplasia compared to colonic mucosa from control patients. Stimulated epithelial electrogenic transport through individual prostanoid subtype receptors EP1, EP2, EP3, and EP4 is not significantly different between neoplasia diseased patients and controls. This indicates that increased indomethacin-sensitive mechanisms in colonic mucosa from neoplasia diseased patients are not related to differences in functional expression of EP receptor subtypes.

\section{Background}

Colorectal cancer $(\mathrm{CRC})$ is the third most common type of cancer and the second leading cause of death among cancers in the Western world [1]. Therapy is usually through surgery, which in severe cases is followed by chemotherapy [2]. There is a need for additional medical therapy and prevention of $\mathrm{CRC}$, which necessitates

\footnotetext{
* Correspondence: mbh@dadlnet.dk
'Department of Surgery K, Bispebjerg Hospital, University of Copenhagen,

* Correspondence: mbh@dadlnet.dk
'Department of Surgery K, Bispebjerg Hospital, University of Copenhagen, Copenhagen, Denmark
}

(c) 2010 Kaltoft et al; licensee BioMed Central Ltd. This is an Open Access article distributed under the terms of the Creative Commons Attribution License (http://creativecommons.org/licenses/by/2.0), which permits unrestricted use, distribution, and reproduction in any medium, provided the original work is properly cited.

further insight into the presently poorly understood mechanisms of colorectal mucosal defence, repair and carcinogenesis. In particular, the mechanisms and signal pathways of pre-neoplastic colorectal epithelial cells are of special interest as these could be target for pharmacotherapy in the prevention of colorectal neoplasia (CRN) and CRC.

By their inhibitory action on the cyclooxygenase enzyme (COX), non-steroidal anti-inflammatory drugs (NSAIDs) are partly chemopreventive against CRC, an effect maybe particularly due to attenuation of the 
enzyme isoform 2 (COX-2) [3-6]. This protection is believed to be mediated, at least in part, through reduction of prostaglandin $\mathrm{E}_{2}\left(\mathrm{PGE}_{2}\right)$ levels $[7,8]$, as $\mathrm{PGE}_{2}$ promotes cell growth, migration and angiogenesis and reduce apoptosis [4]. In general, the downstream cascades of the $\mathrm{PGE}_{2}$ signaling are altered (due to gene mutations) in CRN [9-11]. These mutations may both affect $\mathrm{PGE}_{2}$ production per se via a regulation of $\mathrm{COX}$ enzymes in pro-inflammatory cells including epithelial cells as well as the $\mathrm{PGE}_{2}$-dependent signaling pathways in target cells, Figure 1. Whether changes in levels of $\mathrm{PGE}_{2}$ are primary or secondary causes of CRN remains unclear. With respect to $\mathrm{PGE}_{2}$ receptors, $\mathrm{CRC}$ cells and their neighboring cells have augmented expression of receptors EP2 and EP4, while initially the EP3 receptor expression often is lowered [4,8,12-15], Figure 1.

$\mathrm{PGE}_{2}$ is the primary endogenous agonist for the EP receptors and stimulates all $4 \mathrm{EP}$ receptor subtypes [16]. Butaprost is a selective EP2 agonist [16]. Sulprostone is mainly an EP3 agonist but it is also a weak agonist of EP1 [16]. $\mathrm{PGE}_{1}(\mathrm{OH})$ is mainly an EP4 agonist but it is also a weak agonist of EP3 [16].

Studies of transport mechanisms in human intestinal epithelia in vivo require invasive bothersome procedures. In order to circumvent these problems, the Modified Ussing Air-Suction (MUAS) chamber has been developed for the study of duodenal and colonic epithelia in vitro $[17,18]$. Fairly easily, this method enables us to study epithelial electrogenic ion transport in human biopsies obtained during endoscopy and has been proven useful for functional receptor studies [19].

In this study we sought to establish possible differences in functional expression/response of $\mathrm{PGE}_{2} \mathrm{EP}$ receptor subtypes in colonic biopsies from CRN patients and control subjects by the use of indomethacin, $\mathrm{PGE}_{2}$ and selective EP receptor agonists. Our findings indicate that normally appearing colon in CRN patients, including CRC patients, express higher COX enzyme activity than in control patients but with no difference in the functional expression of the four EP receptor subtypes with respect to transepithelial ion transport.

\section{Methods}

\section{Study population}

Patients referred for colonoscopy were asked to participate. Patients agreeing were pooled into the neoplasia group (i.e. N-patients) if they presented a history of CRN or if CRN was macroscopically detected during colonoscopy. Patients with no previous history or present endoscopic signs of CRN served as controls (i.e. C-patients). Patients with haemorrhagic diathesis, inflammatory bowel disease or previous sigmoid resection were excluded from the study. A total of 63 patients were enrolled, hereof 45 $\mathrm{C}$-patients and $18 \mathrm{~N}$-patients. Among the C-patients the mean age was 59 years and the fraction of men was $41 \%$. In the $\mathrm{N}$-patients group the mean age was 55 years and $32 \%$ were men. We noted patients' medication, body mass index, previous illness, all signs of earlier colorectal disease and the findings from the colonoscopy at the time of examination. During colonoscopy, biopsy specimens were obtained from each patient. Biopsies were pinched from normally appearing mucosa, $30 \mathrm{~cm}$ orally from the anus on retraction of the endoscope. Standard biopsy forceps (Boston Scientific, Radial Jaw 3, outside diameter of 2.2 $\mathrm{mm}$ ) were used. Biopsies were placed in iced Ringer-solution and immediately transferred to the laboratory for mounting in MUAS chambers.

\section{Ethics}

The study protocol was approved by the Scientific Ethical Committee for Copenhagen (KA 97161) and Frederiksberg Counties (KF01-232/03) and conducted in accordance with the Helsinki declaration. All patients participating gave written informed consent.

\section{Mounting of biopsies and electrical measurements}

Biopsies were mounted within 30 minutes in the validated MUAS chambers [18]. Mounting was carried out at 10 times magnification by means of a stereomicroscope to secure mucosa-serosal orientation and proper fixation. The exposed tissue area was $3.4 \mathrm{~mm}^{2}$. Both sides of the tissue were bathed in bicarbonate-Ringer solution containing the following in $\mathrm{mM}: 140 \mathrm{Na}^{+}, 4 \mathrm{~K}^{+}$, $121 \mathrm{Cl}^{-}, 1 \mathrm{Ca}^{2+}, 0.5 \mathrm{Mg}^{2+}, 0.5 \mathrm{SO}_{4}{ }^{2-}, 25 \mathrm{HCO}_{3}{ }^{-}$, and oxygenated with $95 \% \mathrm{O}_{2} / 5 \% \mathrm{CO}_{2}$, circulated by gas-lift. Media were further added $11 \mathrm{mM}$ D-glucose at the serosal side and $11 \mathrm{mM} \mathrm{D}$-sorbitol at the mucosal side. Temperature was maintained at $37^{\circ} \mathrm{C}$ by water jackets. Short circuit current (SCC, $\mu \mathrm{A} \cdot \mathrm{cm}^{-2}$ ) and slope conductance $\left(\mathrm{G}, \mathrm{mS} \cdot \mathrm{cm}^{-2}\right)$ were recorded continuously using an automated voltage-clamp device [17]. Correction for the resistance in solutions was performed immediately before each new specimen was mounted. Our technique of fixing colonic biopsies with air-suction through a 40 $\mu \mathrm{m}$ width suction-sleeve results in fairly high slope conductance most likely due to an edge-leak around the rim of the disk aperture. Conversely, the fixing method reduces potential edge damage of the tissue $[17,18]$. Problems that are related to an edge-leak may be minimized, by performing an accurate solution correction just prior to insertion of the biopsy. Thus, in comparison with other studies on human colonic biopsies [20] the present technique has a high edge-leak conductance but with reduced edge damage. Therefore, our suction system is very sensitive to minute interferences as indicated by the "noise" in the SCC signals in Figure 2. Meanwhile, on the premises of correct solution correction and voltage clamping, the absolute values of druginduced differential changes in SCC should be valid and allow quantitative comparison from tissue to tissue. 


\section{Changes of $\mathrm{PGE}_{2}$ metabolism and signaling efficiency in $\mathrm{CRC}$}

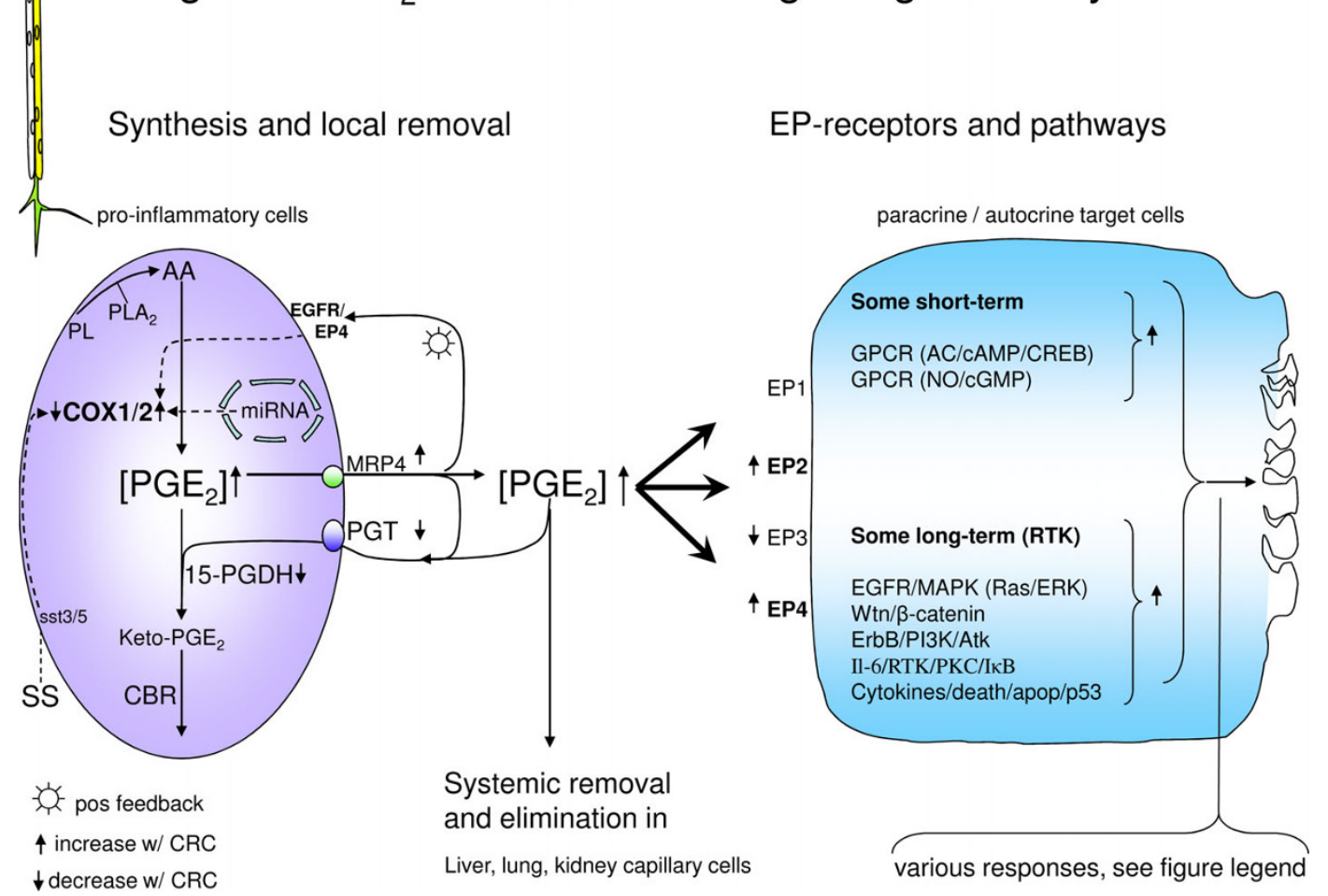

Figure 1 The synthesis, control of tissue level and signalling pathways for $\mathrm{PGE}_{\mathbf{2}}$ is presented. The control of tissue level of $\mathrm{PGE} \mathrm{E}_{2}$ is both through synthesis of $\mathrm{PGE}_{2}$ by the COX enzyme in and its export from pro-inflammatory cells as well as by the removal of $\mathrm{PGE}_{2}$ from the intercellular space by prostaglandin transporter, PGT, and the efficiency of catabolism of $\mathrm{PGE}_{2}$ by enzymes such as 15-prostaglandin dehydrogenease. For instance, expression of the COX-2 enzyme is regulated through many pathways of which several are affected in CRC. As examples of this, somatostatin, SS, has a dampening effect on COX-2 expression, while an autocrine pathway through an epidermal growth factor receptor, EGFR, an EP4 receptor, and microRNA stimulation increase the expression and/or activity of the enzyme. Furthermore, the activity in $\mathrm{PGE}_{2}$-signalling pathways may vary with the expression of the $\mathrm{PGE}_{2}$ receptor subtypes, EP1, EP2, EP3 and EP4, which is affected in CRC. Removal of $\mathrm{PGE}_{2}$ from the extracellular compartment around target cells is by diffusion to the blood stream and uptake and degradation in lung, liver and kidney endothelial cells. Different cellular signalling pathways for $\mathrm{PGE}_{2}$ operation are indicated in the target cell. The activity in various short-term and long-term pathways, as indicated in the target cell, is increased with the CRN/CRC conditions and therefore affecting a host of cell responses, including ion secretion. "Various responses" as mentioned in the figure refers to differentiation, proliferation, survival/ apoptosis, exocrine secretion, altered immune response, invasiveness/metastasis, angiogenesis. Abbreviations: $\mathrm{AA}=$ arachidonic acid, $\mathrm{CBR}=$ carbonyl reductase - also involved in degradation of $\mathrm{PGE}_{2}, \mathrm{COX} 1 / 2=$ cyclooxygenase isoforms 1 and 2, EGFR = epidermal growth factor receptor, $\mathrm{GPCR}=\mathrm{G}$ protein-coupled receptors, miRNA = microRNA, MRP4 = multi-drug resistance related polypeptide 4 - example of an $\mathrm{ABC}$ export pump, $15-\mathrm{PGDH}=15$-prostaglandin dehydrogenase, $\mathrm{PGT}=$ prostaglandin transporter, $\mathrm{PL}=$ phospholipid, $\mathrm{PLA} \mathrm{A}_{2}=$ phospholipase $\mathrm{A}_{2}, \mathrm{RTK}=$ tyrosine kinase receptor pathway, $\mathrm{SS}=$ somatostatin, sst3/5 = somatostatin subtype receptor 3 or 5 .

Experiments were performed after an equilibration period of 15 minutes. Various stimulators (forskolin or theophylline) and inhibitors (indomethacin, bumetanide or ouabain) of epithelial ion transport, as well as EP receptor agonists $\left(\mathrm{PGE}_{2}, \mathrm{PGE}_{1-}-(\mathrm{OH})\right.$, butaprost or sulprostone) were then added separately to the serosal bathing solution, except for indomethacin, which was added to both sides. Indomethacin was always added 15 minutes prior to the addition of EP receptor agonists in order to minimize tissue prostaglandin production. Choices of concentration for the various drugs were based on experience from previous studies [18,21]. Bumetanide was added after EP agonist experiments on the biopsies had been completed. Forskolin or ouabain was added at the end of the experiment as a control of biopsy viability.

\section{Compounds}

All drugs were purchased from Sigma (Vallensbaek Strand, Denmark) except for bumetanide, which was a gift from Leo Pharmaceuticals, Denmark.

\section{Medication and co-morbidity}

At the time of the examination, one patient was medicated with corticosteroids, two with laxatives, three with selective serotonin reuptake inhibitors and other three with NSAIDs, all on a daily basis. Two N-patients had previous resections of the transverse or ascending colon 


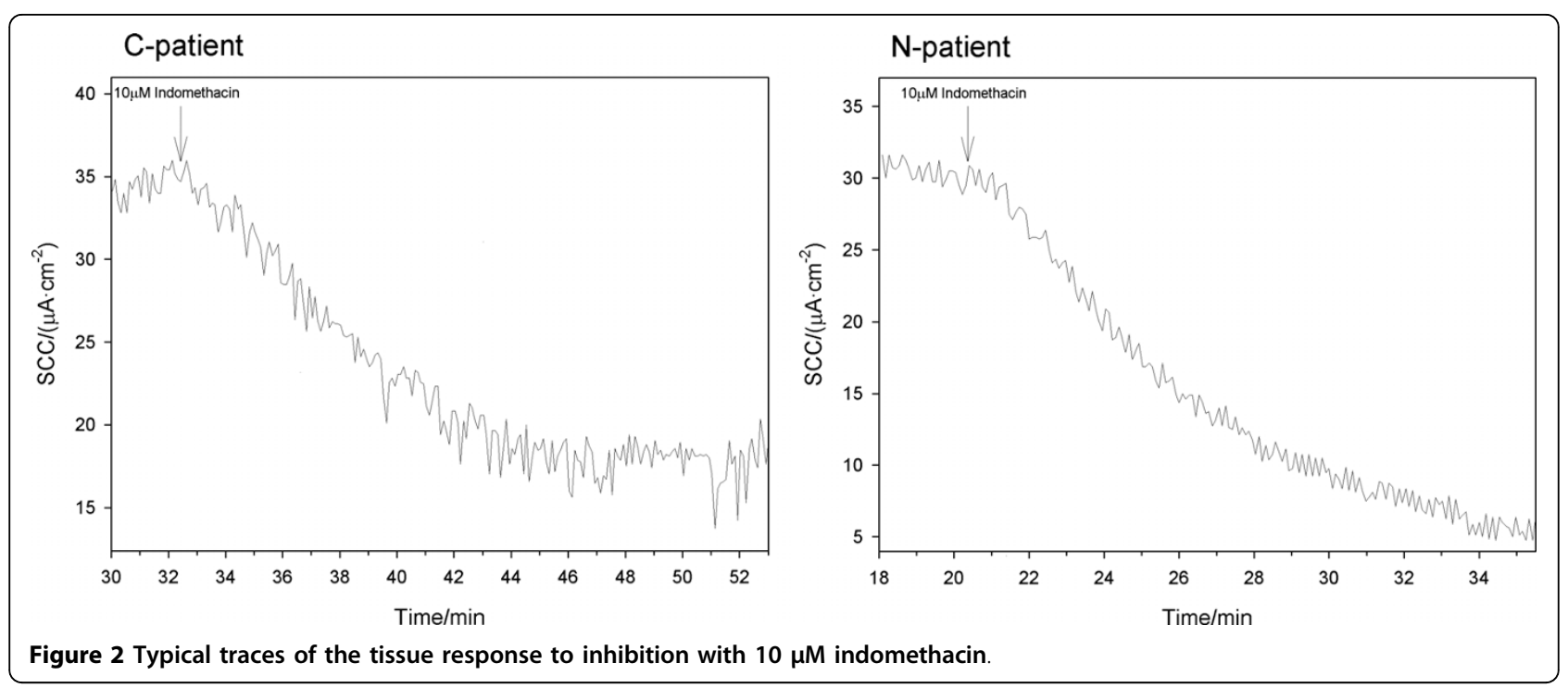

for neoplasia. Results for medicated patients fell within the range of other patients (data not shown).

\section{Data and statistical analysis}

Data are presented as mean \pm SEM (number of biopsy specimens, number of patients). Wilcoxon Rank-sum test or unpaired t-test was used for the calculation of the p-values, depending on the results of the normality test and the equal variance test. P-values less than 5\% were considered significant. All statistics was done on SigmaStat 2.03 for Windows, SPSS Inc., USA.

\section{Histological examination}

Following mounting and stimulation in the MUAS chamber, biopsies considered for histological examination were fixed in $4 \%$ buffered paraformaldehyde. After embedding the tissue samples in paraffin, they were cut into $10-\mu \mathrm{m}$ sections and stained with haematoxylin/periodic acid Schiff for examination in a Leitz Ortoplan microscope (Wetzlar, Germany). Protocols were blinded to the examiner.

\section{Results}

\section{Basal levels}

$\mathrm{N}$-patients baseline values did not differ as compared to $\mathrm{C}$-patients. The baseline SCC in the $\mathrm{C}$-patients was 38.1 $\pm 7.6 \mu \mathrm{A} \cdot \mathrm{cm}^{-2}(97,36)$ and in $\mathrm{N}$-patients $41.3 \pm 15.3$ $\mu \mathrm{A} \cdot \mathrm{cm}^{-2}(39,14), \mathrm{p}=0.70$. Baseline $\mathrm{G}$ in C-patients was $91.2 \pm 6.3 \mathrm{mS} \cdot \mathrm{cm}^{-2}(94,36)$ compared to $90.4 \pm 8.1$ $\mathrm{mS} \cdot \mathrm{cm}^{-2}(39,14)$ in the $\mathrm{N}$-patients, $\mathrm{p}=0.78$. The slope conductance was followed through experiments to ensure stable fixation. An annotated statement on the relatively high conductance values is given in the "Methods" section.

\section{Stimulation}

There were no significant differences between $\mathrm{N}$ patients and C-patients in the induced SCC when stimulating with either $\mathrm{PGE}_{2}(200 \mathrm{nM})$, butaprost $(1.5$ $\mu \mathrm{M})$, sulprostone $(1 \mu \mathrm{M}), \mathrm{PGE}_{1}(\mathrm{OH})(375 \mathrm{nM})$, theophylline $(400 \mu \mathrm{M})$ or forskolin $(1 \mu \mathrm{M})$, Figures 3 and 4 . Half-times for the SCC stimulation were equal in the two groups and lumped here for both $\mathrm{N}$ - and $\mathrm{C}$ patients: $\mathrm{PGE}_{2} 144 \pm 23 \mathrm{~s}(14,8)$, butaprost $221 \pm 11 \mathrm{~s}$ $(23,15), \mathrm{PGE}_{1}(\mathrm{OH}) 191 \pm 15 \mathrm{~s}(16,10)$, sulprostone 108 $\pm 15 \mathrm{~s}(21,13)$, theophylline $139 \pm 9 \mathrm{~s}(36,22)$, and forskolin $304 \pm 11$ s $(58,30)$.

\section{Inhibition}

The SCC in N-patient biopsies were significantly more sensitive to indomethacin $(10 \mu \mathrm{M}), \mathrm{p}=0.027$, compared to $\mathrm{C}$-patients. There were no significant differences between $\mathrm{N}$-patients and $\mathrm{C}$-patients with respect to the inhibiting effect of bumetanide $(50 \mu \mathrm{M})$ or ouabain $(200$ $\mathrm{nM}$ ), Figure 5. Halftimes for the inhibition of SCC were equal for $\mathrm{N}$ - and $\mathrm{C}$-patients and lumped together: for indomethacin $170 \pm 11 \mathrm{~s}(64,36)$, for bumetanide $64 \pm 8$ $\mathrm{s}(20,12)$ and for ouabain $131 \pm 13 \mathrm{~s}(18,12)$. While the drug-elicited changes in SCC amplitude may vary between groups of patients, the lack of difference between $\mathrm{N}$ - and $\mathrm{C}$-patients in response halftimes for stimulation and inhibition of SCC is simply indicating that the same mechanism is affected in the biopsies by each individual drug.

\section{Histological examination}

Histological assessments of previously mounted biopsies were performed for the extent of tissue pathology, edge damage and the thickness of biopsies. The damage found in biopsies were denoted by a severity score ranging from 0 to 4; 0 being severe mucosal damage and 4 being no mucosal damage; as previously described [18]. No difference in histology was detectable for $\mathrm{N}$-patients as compared to C-patients, data not shown. In particular, no signs of inflammation or neoplasia were detected 


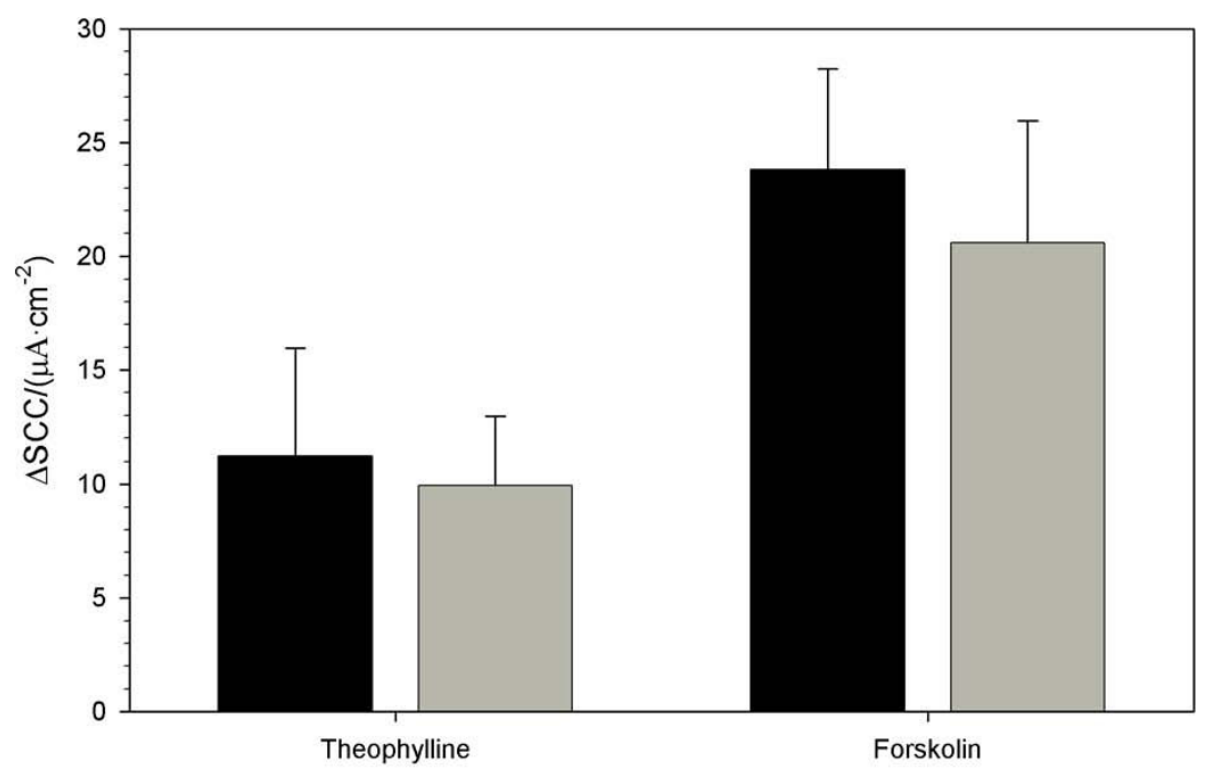

Figure 3 Theophylline and forskolin-stimulated short circuit current (SCC) in human colon endoscopic biopsies from C-patients and Npatients is presented. Numbers in parenthesis are numbers of biopsy specimens and number of patients. Increases in SCC after stimulation with $400 \mu \mathrm{M}$ theophylline (C-patients: 29,18), (N-patients: 7,4) and $1 \mu \mathrm{M}$ forskolin (C-patients: 45,23), (N-patients: 13,7).

in the biopsies from $\mathrm{N}$-patients. Histological examination showed good correlation between mucosa damage and electrical parameters. Thus, disrupted mucosal layers were almost always non-responding to stimulation and inhibition in the MUAS chambers. Biopsies scoring $0-1 \mathrm{had}$ an average increase in SCC of $2.8 \pm 2.0 \mu \mathrm{A} \cdot \mathrm{cm}^{-2}$ $(53,29)$ in response to stimulation with forskolin, which was significantly less compared to an average of $20.5 \pm$ $4.0 \mu \mathrm{A} \cdot \mathrm{cm}^{-2}(56,25)$ in the biopsies scoring $2-4, \mathrm{p}<$ 0.001 .

\section{Discussion}

The present study provides evidence that electrogenic transport is altered in histological normal appearing colonic mucosa in CRN patients with respect to indomethacin-sensitive mechanisms. This finding supports that NSAID-sensitive mechanisms are activated not only in tumor tissue [22] but also in normal appearing tissue.

Levels of $\mathrm{PGE}_{2}$ in the para-/auto-crine milieu are elevated in CRN [23-25] and the clinical benefits of reducing $\mathrm{PGE}_{2}$ levels for $\mathrm{CRC}$ has been documented [5,22,26-30]. Accordingly, related therapeutic strategies are suggested $[31,32]$. But what are the mechanisms for the elevated $\mathrm{PGE}_{2}$ levels in CRN and how do we explain the effect of indomethacin in the present study?
Several enzymes and regulatory pathways control the level of $\mathrm{PGE}_{2}$ both in colonic cells and in the intercellular environment of colonic tissue, Figure 1. In particular, it appears that the COX-2 enzyme expression and hence its activity is elevated in human colonic carcinogenic cells [27,33-35]. Activation of COX-2 enzymes leads to an immediate increase in the intracellular level of $\mathrm{PGE}_{2}$, Figure 1. Regulation of the COX-2 expression is simultaneously controlled by a host of intracellular and extracellular signaling pathways [35-37], Figure 1. In addition, the extracellular concentration of $\mathrm{PGE}_{2}$ is controlled by several other means. Increasing the extracellular $\mathrm{PGE}_{2}$ through prostaglandin secretion in $\mathrm{ABC}$ efflux transporters, MRP4 and MOAT, is probably augmented by elevated activity in the MRP4 transporter as found in CRC cells, Figure 1[38]. Removal of extracellular $\mathrm{PGE}_{2}$ is partially performed by a specific prostaglandin transporter, $\mathrm{PGT}$, and further degradation of $\mathrm{PGE}_{2}$ is by the enzymes 15-prostaglandin-dehydrogenase, 15-PGDH, and carbonyl reductase, CBR, of which, both the activity by PGT and 15-PGDH are reduced in CRC cells, Figure $1[3,38,39]$. Additional support for the involvement of altered15-PGDH enzyme activity in CRC development was recently documented in a mouse model of 15PGDH -/-mouse demonstrating resistance to COX-2- 


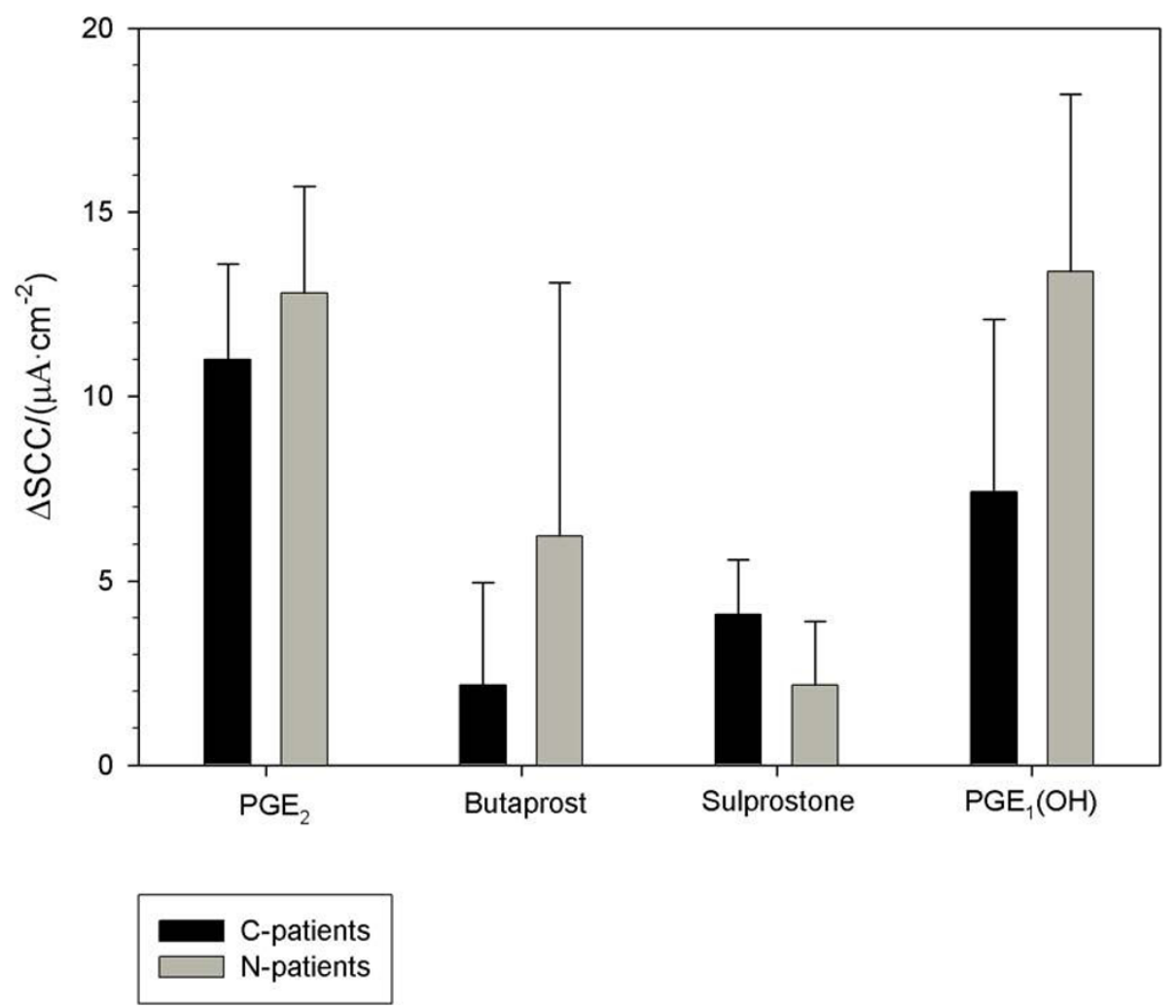

Figure 4 EP receptor subtype agonists ( $\mathrm{PGE}_{2}$, butaprost, sulprostone, and $\mathrm{PGE}_{1}-(\mathrm{OH})$ )-stimulated short circuit current (SCC) in human colon endoscopic biopsies from C-patients and $\mathbf{N}$-patients is presented. Numbers in parenthesis are numbers of biopsy specimens and number of patients. Increases in SCC after stimulation with 200 nM PGE 2 (C-patients: 8,5), (N-patients: 6,3); $1.5 \mu$ M butaprost (C-patients: 12,10), (N-patients: 11,5); $1 \mu \mathrm{M}$ sulprostone (C-patients: 11,7), (N-patients: 10,6) and 375 nM PGE $1-(\mathrm{OH})$ (C-patients: 7,6), (N-patients: 9,4).

inhibitor celecoxib' prevention of colon tumors [40]. Thus, the combined effects of increased synthesis and export together with reduced elimination and degradation of extracellular $\mathrm{PGE}_{2}$ in $\mathrm{CRC}$ point to a maintained higher level of $\mathrm{PGE}_{2}$ in the auto-/paracrine milieu in the CRC colonic epithelium, Figure 1. Interestingly, indomethacin down-regulates the expression of some of the $A B C$ transporters, which are up regulated in CRC $[38,41]$. Therefore several mechanisms could account for indomethacin in regulating the bioavailability of $\mathrm{PGE}_{2}$.

In the present study we found no difference in basal electrogenic transport values or in the response to stimulation with $\mathrm{PGE}_{2}$ or EP receptor subtype specific agonists. Thus, the observed altered expression of EP receptor subtypes in CRC patients compared to nonCRC subjects does not seem to be manifest in the functionality of the receptors in epithelial transport. We speculate that the observed increased sensitivity to indomethacin in the $\mathrm{N}$-patients is due to a higher baseline production of prostaglandins in N-patients following an increased expression/activity of the COX-2 enzyme and export of $\mathrm{PGE}_{2}[27,38]$ and/or a lowered removal and degradation of $\mathrm{PGE}_{2}$, Figure $1[38,39]$. This would be consistent with the lack of differences between specific agonists of the EP receptors as well as still explaining the chemopreventive effect of the NSAIDs. To prove the involvement of the isoform COX-2 as a direct link to our findings, experiments with a specific COX-2 inhibitor would be required.

Although there is no significant difference in the baseline secretion measured as SCC between N-patients and $\mathrm{C}$-patients, the basal current is nearly three times higher than the indomethacin-induced lowering of the current. The significantly higher (5 to $6 \mu \mathrm{A} \cdot \mathrm{cm}^{-2}$ ) differential inhibition of the basal current by indomethacin in $\mathrm{N}$ patients compared to C-patients is not discernable as a significant difference in the basal SCC as such. Biopsies from N-patients had a mere non-significant $\left(3.3 \mu \mathrm{A} \cdot \mathrm{cm}^{-}\right.$ ${ }^{2}$ ) higher value of SCC in the total basal current compared to C-patients. A straight forward explanation for this lack of significance is that the total basal current is most likely a sum of several different electrogenic transport processes including amiloride-sensitive sodium absorption and $\mathrm{Ca}^{2+}$-induced anion secretion, not accounted for in the indometacin-sensitive transport. This is substantiated by a partial inhibition of the 


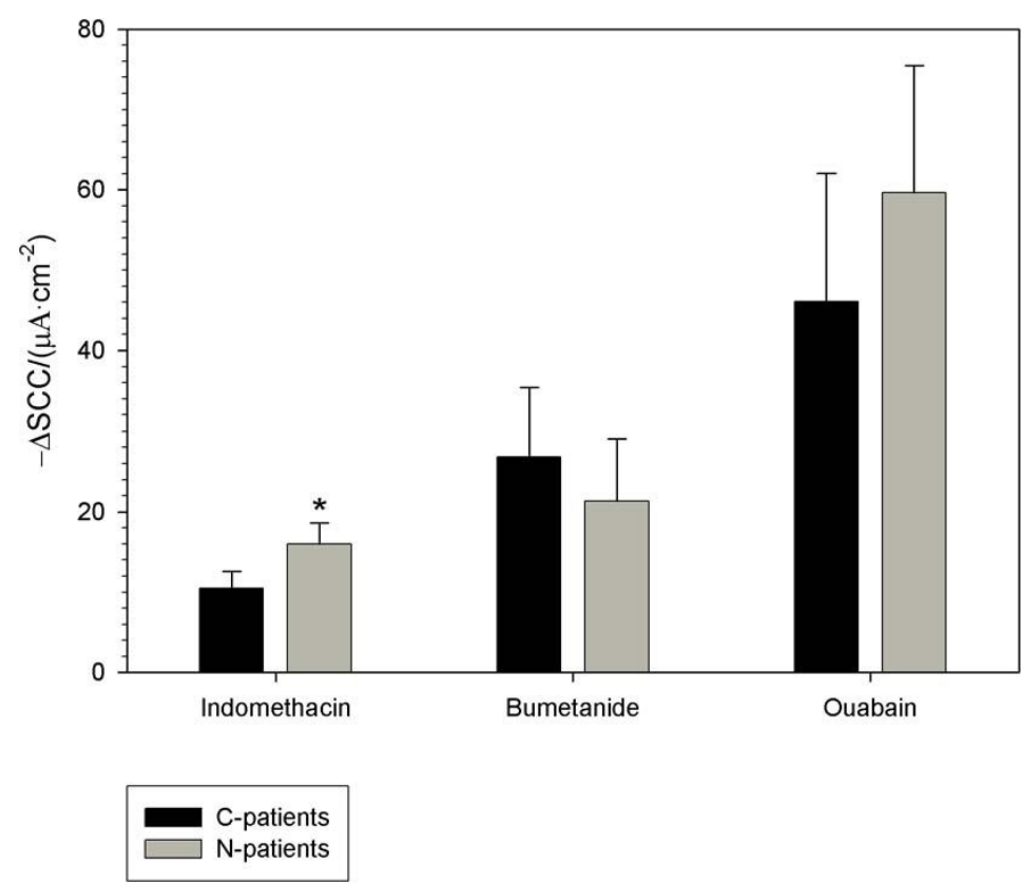

Figure 5 Indomethacin, bumetanide, and ouabain-induced inhibition of short circuit current in human colon biopsies. Inhibition of electrogenic secretion in endoscopic mucosal biopsies from the sigmoid part of colon from C-patients and N-patients. Numbers in parenthesis are numbers of biopsy specimens and numbers of patients. Decreases in short circuit current (SCC) after inhibition with $10 \mu \mathrm{M}$ indomethacin (Cpatients: 43,24), (N-patients: 21,12); $50 \mu \mathrm{M}$ bumetanide (C-patients: 12,7), (N-patients: 8,5) and $200 \mathrm{nM}$ ouabain (C-patients: 10,7), (N-patients: 8,5). ${ }^{*}$ $p<0.05$.

current by bumetanide and an even higher inhibition of the total current by ouabain compared to indomethacin inhibition, Figure 5. Thus a significant difference in a single transport type, as for indomethacin, is possibly smeared to insignificance by its inclusion in the total basal current with a higher variability.

Of the four employed EP receptor agonists, $\mathrm{PGE}_{2}$ induced the largest increase in SCC (i.e. electrogenic secretion), which is not surprising as $\mathrm{PGE}_{2}$ stimulates all four EP receptor subtypes. EP4 seems to be the receptor subtype that is responsible for the largest proportion of this secretion, as stimulation with $\mathrm{PGE}_{1}(\mathrm{OH})$ brought about the largest increase in secretion. This fits with findings in the human duodenum using the same experimental technique [19]. Similar mechanisms appear to be present in rat colon, but in contrast to rats, where EP4 is the major mediator of the $\mathrm{PGE}_{2}$ response [21], the human colon $\mathrm{PGE}_{2}$-induced secretion seems to be induced by all four receptor subtypes, EP4, EP2 and EP1/EP3, Figure 4. This underlines the notable difference of functional EP receptors in some animals as compared to man. However, in agreement with findings in rat colon [21], $\mathrm{PGE}_{2}$ was found to be only a partial agonist of secretion, as forskolin almost doubled the electrogenic secretory response of $\mathrm{PGE}_{2}$. It is not possible to make any final conclusions regarding the observed differences between human and rat colon, although species or regional characteristics might explain the observed differences.

The $\mathrm{PGE}_{1}$-derivative Lubiprostone is used clinically as a laxative. Besides its prokinetic effect, Lubiprostone is also believed to be a chloride channel, $\mathrm{ClC}-2$, opener and now further a stimulant of EP4 receptor subtypes in human ileum and colon epithelium chloride secretion, dependent on a well-functioning cystic fibrosis transmembrane conductance regulator protein, CFTR [42], as well as of the EP4 receptor subtype in human and rat duodenal epithelial bicarbonate secretion $[19,43]$. This information corroborates our use of $\mathrm{PGE}_{1}(\mathrm{OH})$ as a rather specific EP4 receptor subtype agonist and that this receptor subtype is the major pathway for $\mathrm{PGE}_{2}-$ induced colonic anion secretion in man, Figure 4.

\section{Conclusion}

Epithelial electrogenic transport is altered in histological normal appearing colonic mucosal biopsies from patients with previous or present colorectal neoplastic disease with respect to indomethacin-sensitive mechanisms. The mode of action for the observed effect of indomethacin does not seem related to the functionality of expressed prostaglandin EP receptor subtypes, EP1-4, when compared with non-neoplastic patient tissues. 
Therefore, our results point directly to a change in the activity of COX enzymes in the normal colonic tissue from patients with neoplasia, although at present we cannot differentiate between the isoform of COX enzymes possibly being involved. To do this selective COX-1 and COX-2 inhibitors would have to be tested.

\section{Abbreviations}

COX: cyclooxygenase; COX-2: cyclooxygenase isoform 2; C-patients: controlpatients; CRC: colorectal cancer; CRN: colorectal neoplasia; G: slope conductance; MUAS: Modified Ussing Air-Suction; NSAIDs: non-steroidal antiinflammatory drugs; $\mathrm{N}$-patients: neoplasia-patients; $\mathrm{PGE}_{2}$ : prostaglandin $\mathrm{E}_{2 i}$ SCC: short circuit current; SEM: standard error of the mean.

\section{Acknowledgements}

We thank the staff at the Gastrointestinal Endoscopy Unit at Bispebjerg Hospital, University of Copenhagen for great support. This work was supported by grants from Snedkermester Sophus Jacobsen and Wife Astrid Jacobsens Foundation, Else and Mogens Wedell-Wedellsborgs Foundation, and the Karolinska Institute Faculty Foundation in Stockholm.

\section{Author details}

'Department of Surgery K, Bispebjerg Hospital, University of Copenhagen, Copenhagen, Denmark. ${ }^{2}$ Department of Gastroenterology and Hepatology, Karolinska University Hospital, Stockholm, Sweden. ${ }^{3}$ Department of Anatomy B, Panum Institute, University of Copenhagen, Copenhagen, Denmark. ${ }^{4}$ Department of Biomedical Sciences, Panum Institute, University of Copenhagen, Copenhagen, Denmark. ${ }^{5}$ AstraZeneca, Research \& Development, Mölndal, Sweden.

\section{Authors' contributions}

NK carried out Ussing chamber studies, participated in the design of the study, performed statistical analysis and helped to draft the manuscript. CT and PSO carried out Ussing chamber studies and participated in the design of the study. ABW carried out Ussing chamber studies, performed statistical analysis and helped draft the manuscript. SSP carried out histoanatomical studies. MBH and NB conceived the study and helped draft the manuscript All authors read and approved the final manuscript.

\section{Competing interests}

The authors declare no competing interests. After completion of the study Mark Berner Hansen was employed at AstraZeneca Research \&

Development.

Received: 3 June 2009

Accepted: 26 January 2010 Published: 26 January 2010

\section{References}

1. Gupta RA, Dubois RN: Colorectal cancer prevention and treatment by inhibition of cyclooxygenase-2. Nat Rev Cancer 2001, 1:11-21.

2. Jemal A, Siegel R, Ward E, Hao Y, Xu J, Murray T, Thun MJ: Cancer statistics, 2008. CA Cancer J Clin 2008, 58:71-96.

3. Backlund MG, Mann JR, Holla VR, Buchanan FG, Tai HH, Musiek ES, Milne GL, Katkuri S, DuBois RN: 15-Hydroxyprostaglandin dehydrogenase is downregulated in colorectal cancer. J Biol Chem 2005, 280:3217-3223.

4. Chell S, Kaidi A, Williams AC, Paraskeva C: Mediators of PGE2 synthesis and signalling downstream of COX-2 represent potential targets for the prevention/treatment of colorectal cancer. Biochim Biophys Acta 2006, 1766:104-119.

5. Hilmi I, Goh KL: Chemoprevention of colorectal cancer with nonsteroidal anti-inflammatory drugs. Chin J Dig Dis 2006, 7:1-6.

6. Stack E, Dubois RN: Role of cyclooxygenase inhibitors for the prevention of colorectal cancer. Gastroenterol Clin North Am 2001, 30:1001-1010.

7. Bennett A: Prostaglandins as factors in diseases of the alimentary tract. Adv Prostaglandin Thromboxane Res 1976, 2:547-555.

8. Mutoh M, Watanabe K, Kitamura T, Shoji Y, Takahashi M, Kawamori T, Tani K, Kobayashi M, Maruyama T, Kobayashi K, et al: Involvement of prostaglandin E receptor subtype $\mathrm{EP}(4)$ in colon carcinogenesis. Cancer Res 2002, 62:28-32

9. Vogelstein B, Kinzler KW: Cancer genes and the pathways they control. Nat Med 2004, 10:789-799.

10. Lin J, Gan CM, Zhang X, Jones S, Sjöblom T, Wood LD, Parsons DW, Papadopoulos N, Kinzler KW, Vogelstein B, et al: A multidimensional analysis of genes mutated in breast and colorectal cancers. Genome Res 2007, 17:1304-1318.

11. Wood LD, Parsons DW, Jones S, Lin J, Sjöblom T, Leary RJ, Shen D, Boca SM, Barber T, Ptak J, et al: The genomic landscapes of human breast and colorectal cancers. Science 2007, 318:1108-1113.

12. Shoji Y, Takahashi M, Kitamura T, Watanabe K, Kawamori T, Maruyama T, Sugimoto $Y$, Negishi M, Narumiya S, Sugimura T, et al: Downregulation of prostaglandin E receptor subtype EP3 during colon cancer development. Gut 2004, 53:1151-1158.

13. Holla VR, Mann JR, Shi Q, DuBois RN: Prostaglandin E2 regulates the nuclear receptor NR4A2 in colorectal cancer. J Biol Chem 2006, 281:2676-2682.

14. Fujino H, Chen Xb, Regan JW, Murayama T: Indomethacin decreases EP2 prostanoid receptor expression in colon cancer cells. Biochem Biophys Res Commun 2007, 359:568-573.

15. Hawcroft G, Ko CWS, Hull MA: Prostaglandin E2-EP4 receptor signalling promotes tumorigenic behaviour of HT-29 human colorectal cancer cells. Oncogene 2007, 26:3006-3019.

16. Kiriyama M, Ushikubi F, Kobayashi T, Hirata M, Sugimoto Y, Narumiya S: Ligand binding specificities of the eight types and subtypes of the mouse prostanoid receptors expressed in Chinese hamster ovary cells. BrJ Pharmacol 1997, 122:217-224.

17. Larsen R, Mertz-Nielsen A, Hansen MB, Poulsen SS, Bindslev N: Novel modified Ussing chamber for the study of absorption and secretion in human endoscopic biopsies. Acta Physiol Scand 2001, 173:213-222.

18. Osbak PS, Bindslev N, Poulsen SS, Kaltoft N, Tilotta MC, Hansen MB: Colonic epithelial ion transport is not affected in patients with diverticulosis. BMC Gastroenterol 2007, 7:37.

19. Larsen R, Hansen MB, Bindslev N: Duodenal secretion in humans mediated by the EP4 receptor subtype. Acta Physiol Scand 2005, 185:133-140.

20. Mall M, Bleich M, Schurlein M, Kuhr J, Seydewitz HH, Brandis M, Greger R, Kunzelmann K: Cholinergic ion secretion in human colon requires coactivation by cAMP. Am J Physiol 1998, 275:G1274-G1281.

21. Mosa AS, Hansen MB, Tilotta CM, Bindslev N: EP4 and EP2 receptor subtypes involved in colonic secretion in rat. Basic Clin Pharmacol Toxicol 2008, 103:214-221

22. Rostom A, Dubé C, Lewin G, Tsertsvadze A, Barrowman N, Code C, Sampson M, Moher D: Nonsteroidal anti-inflammatory drugs and cyclooxygenase-2 inhibitors for primary prevention of colorectal cancer: a systematic review prepared for the U.S. Preventive Services Task Force. Ann Intern Med 2007, 146:376-389.

23. Pai R, Nakamura T, Moon WS, Tarnawski AS: Prostaglandins promote colon cancer cell invasion; signaling by cross-talk between two distinct growth factor receptors. FASEB J 2003, 17:1640-1647.

24. Greenhough A, Smartt HJM, Moore AE, Roberts HR, Williams AC, Paraskeva C, Kaidi A: The COX-2/PGE2 pathway: key roles in the hallmarks of cancer and adaptation to the tumour microenvironment. Carcinogenesis 2009, 30:377-386.

25. Wang D, DuBois RN: Pro-inflammatory prostaglandins and progression of colorectal cancer. Cancer Lett 2008, 267:197-203.

26. Dubois RN: Nonsteroidal antiinflammatory drugs, cyclooxygenase-2, and colorectal cancer prevention. Curr Opin Gastroenterol 2001, 17:65-71.

27. Brown JR, DuBois RN: COX-2: a molecular target for colorectal cancer prevention. J Clin Oncol 2005, 23:2840-2855.

28. Fulton AM, Ma X, Kundu N: Targeting prostaglandin E EP receptors to inhibit metastasis. Cancer Res 2006, 66:9794-9797.

29. Siemes C, Visser LE, Coebergh JWW, Hofman A, Uitterlinden AG, Stricker BHC: Protective effect of NSAIDs on cancer and influence of COX-2 C(-765G) genotype. Curr Cancer Drug Targets 2008, 8:753-764.

30. Iwama T: NSAIDs and colorectal cancer prevention. J Gastroenterol 2009, 44(Suppl 19):72-76.

31. Doherty GA, Murray FE: Cyclooxygenase as a target for chemoprevention in colorectal cancer: lost cause or a concept coming of age?. Expert Opin Ther Targets 2009, 13:209-218. 
32. Elwood PC, Gallagher AM, Duthie GG, Mur LA, Morgan G: Aspirin, salicylates, and cancer. Lancet 2009, 373:1301-1309.

33. Kawasaki T, Nosho K, Ohnishi M, Suemoto Y, Glickman JN, Chan AT, Kirkner GJ, Mino-Kenudson M, Fuchs CS, Ogino S: Cyclooxygenase-2 overexpression is common in serrated and non-serrated colorectal adenoma, but uncommon in hyperplastic polyp and sessile serrated polyp/adenoma. BMC Cancer 2008, 8:33.

34. McLean MH, Murray GI, Fyfe N, Hold GL, Mowat NAG, El-Omar EM: COX-2 expression in sporadic colorectal adenomatous polyps is linked to adenoma characteristics. Histopathology 2008, 52:806-815.

35. Young LE, Sanduja S, Bemis-Standoli K, Pena EA, Price RL, Dixon DA: The mRNA Binding Proteins HuR and Tristetraprolin Regulate Cyclooxygenase 2 Expression During Colon Carcinogenesis. Gastroenterology 2009, 136:1669-1679.

36. Smith WL, DeWitt DL, Garavito RM: Cyclooxygenases: structural, cellular, and molecular biology. Annu Rev Biochem 2000, 69:145-182.

37. Strillacci A, Griffoni C, Sansone P, Paterini P, Piazzi G, Lazzarini G, Spisni E, Pantaleo MA, Biasco G, Tomasi V: MiR-101 downregulation is involved in cyclooxygenase-2 overexpression in human colon cancer cells. Exp Cell Res 2009, 315:1439-1447.

38. Holla VR, Backlund MG, Yang P, Newman RA, DuBois RN: Regulation of prostaglandin transporters in colorectal neoplasia. Cancer Prev Res (Phila Pa) 2008, 1:93-99.

39. Backlund MG, Mann JR, Holla VR, Shi Q, Daikoku T, Dey SK, DuBois RN: Repression of 15-hydroxyprostaglandin dehydrogenase involves histone deacetylase 2 and snail in colorectal cancer. Cancer Res 2008, 68:9331-9337.

40. Yan M, Myung SJ, Fink SP, Lawrence E, Lutterbaugh J, Yang P, Zhou X, Liu D, Rerko RM, Willis J, et al: 15-Hydroxyprostaglandin dehydrogenase inactivation as a mechanism of resistance to celecoxib chemoprevention of colon tumors. Proc Natl Acad Sci USA 2009, 106:9409-9413.

41. Gradilone A, Pulcinelli FM, Lotti LV, Trifirò E, Martino S, Gandini O, Gianni W, Frati L, Aglianò AM, Gazzaniga P: Celecoxib upregulates multidrug resistance proteins in colon cancer: lack of synergy with standard chemotherapy. Curr Cancer Drug Targets 2008, 8:414-420.

42. Bijvelds MJ, Bot AG, Escher JC, De Jonge HR: Activation of intestinal Clsecretion by lubiprostone requires the cystic fibrosis transmembrane conductance regulator. Gastroenterology 2009, 137:976-985.

43. Mizumori M, Akiba Y, Kaunitz JD: Lubiprostone stimulates duodenal bicarbonate secretion in rats. Dig Dis Sci 2009, 54:2063-2069.

\section{Pre-publication history}

The pre-publication history for this paper can be accessed here:http://www. biomedcentral.com/1471-230X/10/9/prepub

\section{doi:10.1186/1471-230X-10-9}

Cite this article as: Kaltoft et al.: Prostaglandin E2-induced colonic secretion in patients with and without colorectal neoplasia. BMC Gastroenterology 2010 10:9. 